\title{
Silent New Brain Lesions: Innocent Bystander or Guilty Party?
}

\author{
Eun-Jae Lee, ${ }^{a}$ Dong-Wha Kang, ${ }^{a}$ Steven Warach ${ }^{b}$ \\ ${ }^{\mathrm{a}}$ Department of Neurology, Asan Medical Center, University of Ulsan, College of Medicine, Seoul, Korea \\ ${ }^{b}$ Department of Neurology, Dell Medical School, University of Texas at Austin, Austin, TX, USA
}

With the advances in magnetic resonance imaging, previously unrecognized small brain lesions, which are mostly asymptomatic, have been increasingly detected. Diffusion-weighted imaging can identify small ischemic strokes, while gradient echo T2* imaging and susceptibility-weighted imaging can reveal tiny hemorrhagic strokes (microbleeds). In this article, we review silent brain lesions appearing soon after acute stroke events, including silent new ischemic lesions and microbleeds appearing 1) after acute ischemic stroke and 2) after acute intracerebral hemorrhage. Moreover, we briefly discuss the clinical implications of these silent new brain lesions.

Keywords Silent brain lesions; New ischemic lesions; New microbleeds

\author{
Correspondence: Dong-Wha Kang \\ Department of Neurology, Asan Medical \\ Center, University of Ulsan, College of \\ Medicine, 88 Olympic-ro 43-gil, \\ Songpa-gu, Seoul 05505, Korea \\ Tel: +82-2-3010-3440 \\ Fax: +82-2-474-4691 \\ E-mail:dwkang@amc.seoul.kr \\ Received: August 24, 2015 \\ Revised: September 12, 2015 \\ Accepted: September 14, 2015 \\ This research was supported by the \\ National Research Foundation of Korea \\ Grant NRF-2014R1A2A1A11051280 funded \\ by the Korea government, and the Korea \\ Health Technology R\&tD Project, Ministry \\ for Health \& Welfare, Republic of Korea \\ Grants HI12C1847 and HI14C1983. \\ The authors have no financial conflicts of \\ interest.
}

\section{Introduction}

Although most strokes are considered a single event, subsequent strokes may follow shortly after an acute stressful event such as ischemic or hemorrhagic stroke. Remarkably, in many cases, such subsequent strokes after acute index events are asymptomatic. These silent new brain lesions can be demonstrated by diffusion-weighted imaging (DWI) and gradient echo T2* imaging (GRE) or susceptibility-weighted imaging. Although the name suggests clinically silent behaviors, their clinical importance remains controversial. While some researchers consider only clinically obvious stroke as clinically important, ${ }^{1}$ others have associated silent new brain lesions with future strokes or possible harmful effects on the brain function.

In this article, we aim to review silent new brain lesions in terms of their incidence, associated factors, mechanisms, and clinical implications. As both ischemic and hemorrhagic (microbleeds) strokes can appear as silent new brain lesions, this narrative review categorized silent new lesions into two groups: silent new ischemic lesions (SNILs) and silent new microbleeds (SNMs).

\section{SNILS}

\section{SNILs after acute ischemic stroke}

As mortality is increased in stroke patients with early recurrence, ${ }^{2,3}$ efforts have been made to identify patients at high risk of recurrence. To identify these patients in the early phase of the index stroke, DWI, which is the most sensitive imaging method for detecting hyperacute ischemic stroke, ${ }^{4,5}$ has been rigorously 
used to detect early recurrent ischemic lesions.

\section{Definition and incidence}

SNILs can be arbitrarily divided into early and late SNILs based on the time of magnetic resonance imaging (MRI). Early SNILs are usually defined as a new lesion on 5-day to 7-day DWI outside the region of the acutely symptomatic lesion (Table 1) ${ }^{6-14}$ Early SNILs are reportedly found in $24.2 \%-34.3 \%$ of patients with acute ischemic stroke, ${ }^{6-11}$ while higher rates have been reported in patients with large artery atherosclerosis ${ }^{13,14}$ or in those receiving thrombolysis. ${ }^{12}$ These rates of early SNILs largely exceed those of clinical evident recurrence, of which the cumulative rates have been reported to be $2 \%$ within 1 week $^{15}$ and $1.6 \%-8 \%$ in 90 days. ${ }^{16-18}$ Accordingly, the majority of early SNILs are asymptomatic. ${ }^{6-10,13}$

Late SNILs occurring at a subacute stage have also been measured in several studies using DWI and fluid attenuated inversion recovery imaging at 30 or 90 days after the index stroke. ${ }^{7,8}$ In these studies, the incidence of late SNILs was reported as $22.1 \%-26.3 \%$, which is lower than that of early SNILs. However, the majority of late SNILs are also asymptomatic.

\section{Characteristics}

SNILs after acute ischemic stroke can be further categorized into two groups based on their locations, namely "local" or "distant" lesion recurrence according to whether a new lesion occurs within or outside the territory of initial perfusion deficit (Figures 1 and 2). ${ }^{6,7}$ In early SNILs, the proportion of local lesion recurrence is slightly higher than that of distant lesion recurrence (44.4\%-51.9\% vs. $44.1 \%-47.1 \%)$. On the contrary, in late SNILs, local lesion recurrence is less frequent than distant lesion recurrence ( $23.8 \%$ vs. $76.2 \%)$ ?

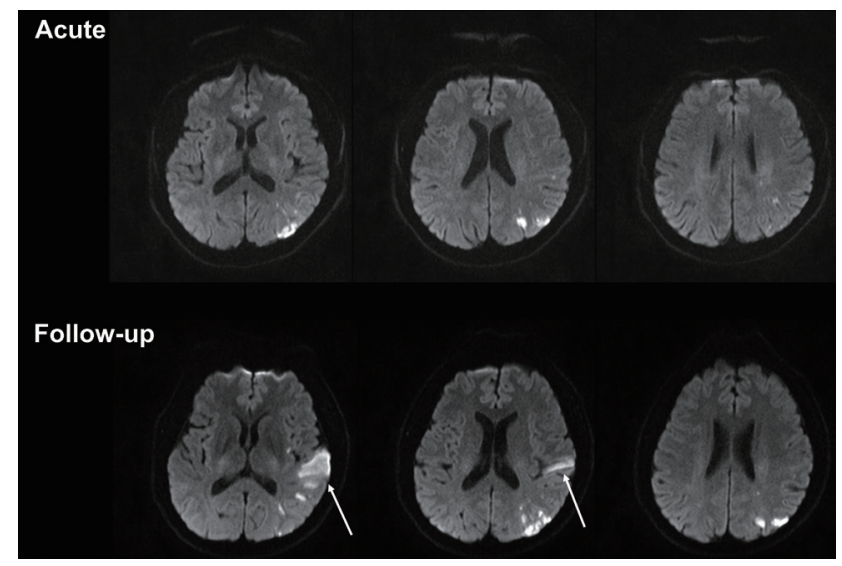

Figure 1. Early local silent new ischemic lesions (SNILs). Acute diffusionweighted imaging (DWI) was performed within 24 hours after symptom onset and follow-up DWI was performed 2 days after the index ischemic stroke. EarIy local SNILs (arrows) are shown on the follow-up DWI.

Table 1. New ischemic lesions after acute ischemic stroke and minor stroke or TIA

\begin{tabular}{|c|c|c|c|c|c|}
\hline Author & Time of follow-up MRI & No. of patients & Incidence of SNILs & Asymptomatic & Factors associated with new ischemic lesions* \\
\hline Kang $^{6}$ & Within 1 week & 99 & $34(34.3 \%)$ & $32(94.1 \%)$ & Initial multiple DWI lesions \\
\hline $\mathrm{Kang}^{7}$ & $\begin{array}{c}\text { Early: } 5 \text { days } \\
\text { Late: } 30 / 90 \text { days }\end{array}$ & 80 & $\begin{array}{c}\text { Early: } 27(33.8 \%) \\
\text { Late: } 21(26.3 \%)\end{array}$ & $\begin{array}{l}\text { Early: } 25(92.6 \%) \\
\text { Late: } 18(85.7 \%)\end{array}$ & Early lesion recurrence (for late lesion recurrence) \\
\hline Kang $^{8}$ & $\begin{array}{l}\text { Early: } 5 \text { days } \\
\text { Late: } 30 / 90 \text { days }\end{array}$ & 104 & $\begin{array}{l}\text { Early: } 35(33.7 \%) \\
\text { Late: } 15(22.1 \% \text { of } 68)\end{array}$ & $\begin{array}{l}\text { Early: } 35(100 \%) \\
\text { Late: } 10(66.7 \%)\end{array}$ & \\
\hline Nolte $^{9}$ & $\begin{array}{l}\text { 2nd: }<48 \text { hours } \\
\text { 3rd: } 5 / 6 \text { days }\end{array}$ & 159 & $46(28.9 \%)$ & $42(91.3 \%)$ & $\begin{array}{l}\text { Carotid stenosis }>50 \% \\
\text { Recanalization } \\
\text { Multiple lesion pattern }\end{array}$ \\
\hline Kang $^{10}$ & 5 days & 153 & $37(24.2 \%)$ & $35(94.6 \%)$ & $\begin{array}{l}\text { Initial multiple DWI lesions } \\
\text { Large artery atherosclerosis } \\
\text { Log D-dimer }\end{array}$ \\
\hline Jeon $^{11}$ & 7 days & 117 & $34(29.1 \%)$ & Not specified & $\begin{array}{l}\text { Biochemical aspirin resistance (for distant early } \\
\text { lesion recurrence) }\end{array}$ \\
\hline Bang $^{12}$ & 7 days & 74 & $39(52.7 \%)$ & Not specified & Large mild perfusion delay, endovascular therapy \\
\hline $\mathrm{Kang}^{13}$ & Within 1 week & 133 & $63(47.4 \%)$ & $55(87.3 \%)$ & \\
\hline Jeong $^{14}$ & 5 days & 76 & $36(47.4 \%)$ & Not specified & A certain CYP2C19 genotype, poor metabolizer \\
\hline \multicolumn{6}{|c|}{ Minor stroke or TIA } \\
\hline Coutts $^{29}$ & 30 days & $143(65 \mathrm{TIA})$ & $14(9.8 \%)$ & $8(57.1 \%)$ & \\
\hline Asdaghi $^{30}$ & 7,30 days & 50 (22 TIA) & $\begin{array}{c}9(18.0 \%) \text { at } 7 \text { days } \\
11(22.0 \%) \text { at } 30 \text { days }\end{array}$ & $6(66.7 \%)$ & Baseline DWI lesion volume \\
\hline $\mathrm{Nah}^{31}$ & $\begin{array}{l}3 \text { days (in 45) } \\
90 \text { days (in 45) }\end{array}$ & $90 \mathrm{TIA}$ & $\begin{array}{c}3 \text { days: } 21 / 45(46.7 \%) \\
90 \text { days: } 3 / 45(6.7 \%)\end{array}$ & $\begin{array}{l}3 \text { days: } 14(66.7 \%) \\
90 \text { days: } 2(66.7 \%)\end{array}$ & \\
\hline
\end{tabular}

*Only variables determined as significant by multivariable analysis.

DWI, diffusion-weighted imaging; MRI, magnetic resonance imaging; SNILs, silent new ischemic lesions; TIA, transient ischemic attack. 


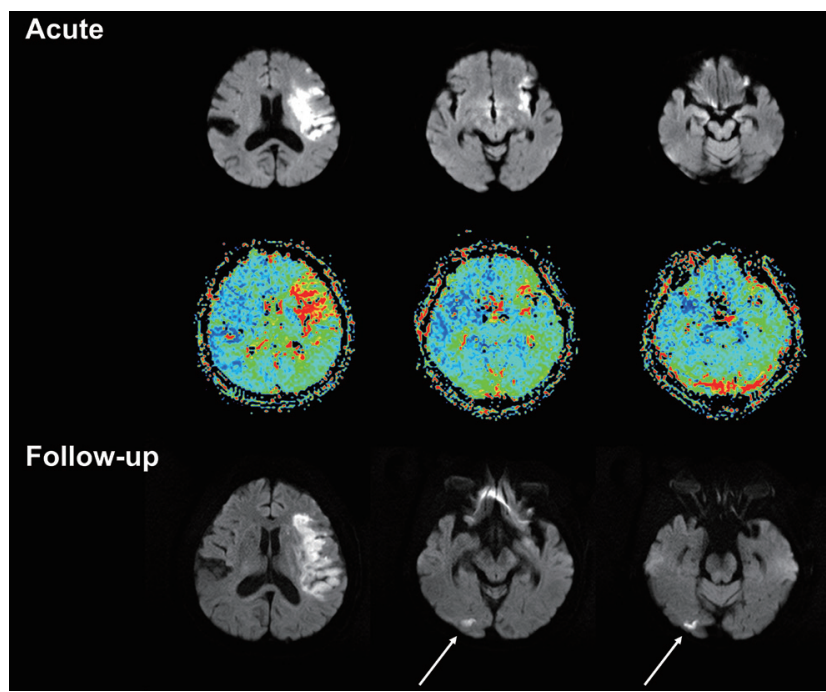

Figure 2. Early distant silent new ischemic lesions (SNILs). Acute diffusionweighted imaging (DWI) and perfusion-weighted imaging were performed within 24 hours after symptom onset. Follow-up DWI was performed 8 days after the index ischemic stroke. Early distant SNILs (arrows) are indicated on the follow-up DWI.

Moreover, the lesion size of most SNILs is small, ${ }^{12,13}$ with the reported lesion volumes ranging between 0.3 and $0.7 \mathrm{~mL},{ }^{13}$ and the majority of SNILs (70.6\%) being $10 \mathrm{~mm}$ or less in diameter. ${ }^{12}$ These findings are consistent with the fact that most recurrent ischemic lesions do not cause any evident symptoms in the patients.

\section{Associated factors and mechanism}

Multiple ischemic lesions on baseline DWI are significantly associated with early SNILs. ${ }^{6,9,10}$ If multiple acute lesions are demonstrated on clinical presentation, especially with varying degree of apparent diffusion coefficient (e.g., reduced and normalized), those lesions may have occurred at varying time points before or after the clinical stroke onset. ${ }^{6,19}$ Moreover, increased microembolic events have been reported to be related with these multiple lesion patterns. ${ }^{20}$

Among the different stroke subtypes, large-artery atherosclerosis (LAA) has been most frequently associated with early SNILs, ${ }^{6,-10,13}$ and has been shown as an independent predictor of SNILs after acute ischemic stroke. ${ }^{10}$ In particular, early SNILs in intracranial LAA have different characteristics compared to other stroke subtypes. ${ }^{13}$ Early SNILs in intracranial LAA occur mostly in the pial area of the same vascular territory as the index stroke and are more frequently observed in higher grades of stenosis. On the other hand, in extracranial LAA, the degree of stenosis is not related to early SNILs, and these are not associated with subsequent recanalization, whereas in cases of cardioembolism, early SNILs are associated with significant recanali- zation. In intracranial LAA, artery-to-artery embolism or hemodynamic insufficiency may play an important role in the pathogenesis of recurrent ischemic stroke. ${ }^{21}$ Meanwhile, plaque heterogeneity and fragmentation of the initial embolus may be more crucial in the pathogenesis of SNILs in extracranial LAA and cardioembolism, respectively. ${ }^{22}$ Lastly, early SNILs in intracranial LAA are more closely associated with clinical recurrence than in the other subtypes. In line with these findings, patients with stroke resulting from intracranial LAA have been demonstrated to show a high risk of recurrent stroke ( $>20 \%$ over 2 years). ${ }^{23}$

Thrombolytic therapy and vessel recanalization have also been shown to be associated with early SNILs. ${ }^{9}, 12$ Chronologically, recombinant tissue-type plasminogen activator treatment is associated with acute SNILs, which occur between 24 and 48 hours, while spontaneous vessel recanalization is associated with subacute SNILs, occurring between 2 and 6 days. ${ }^{9}$ Recombinant tissue-type plasminogen activator treatment can contribute to the occurrence of SNILs by imperfect dissolution of either the embolus at the site of the main vessel occlusion or the thrombus at the site of origin; however, its short half-life may limit its role to only the acute phase.

Regarding the baseline hypoperfusion status, large mild perfusion delays have been shown to be independently associated with early SNILs. Meanwhile, more severe perfusion delays, together with large initial DWI lesion, have been demonstrated to be related with infarct lesion growth in the subsequent DWI within 7 days. ${ }^{12}$

Among the various plasma or serum biomarkers measured within 24 hours after the onset of index stroke, an elevated level of $\mathrm{D}$-dimer has been shown to be independently associated with early SNILs at 5-day. ${ }^{10}$ Increased D-dimer levels may reflect ongoing thrombus formation within cerebral vessels or systemic hypercoagulability. ${ }^{24}$ Moreover, D-dimer itself may induce the inflammatory process by stimulating monocyte synthesis and release of proinflammatory cytokines such as interleukin-6. ${ }^{25}$

Insufficient inhibition of platelet aggregation by the administered drugs may also contribute to the advent of SNILs. ${ }^{11,14}$ Biochemical aspirin resistance, defined as an aspirin reaction unit $\geq 550$ (VerifyNow Aspirin Assay), was associated with distant early SNILs occurring outside the vascular territories of index stroke in one previous study. ${ }^{11}$ In addition, a certain genotype of cytochrome $\mathrm{P} 450$ 2C19, which poorly metabolizes clopidogrel into its active form, has been reported to relate with a significantly higher rate of SNILs in patients with stroke due to LAA. ${ }^{14}$

Taken together, the mechanisms of early or late SNILs are di- 


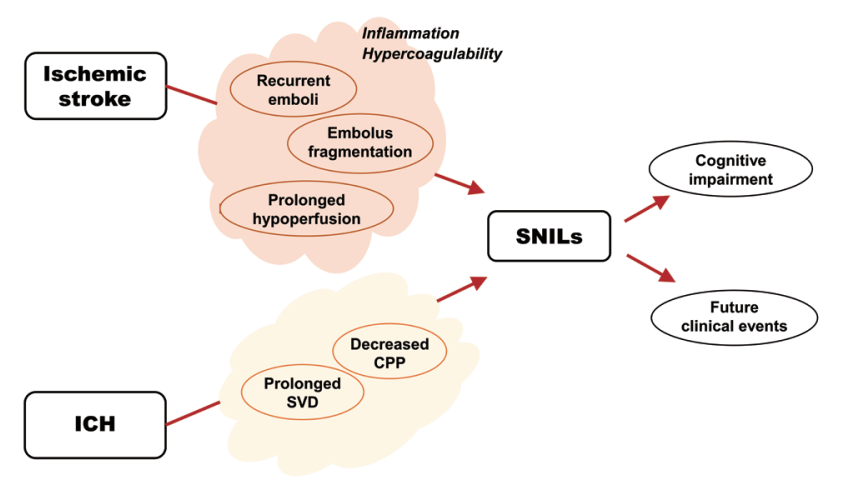

Figure 3. Pathophysiology and clinical implications of silent new ischemic lesions (SNILS) after stroke. CPP, cerebral perfusion pressure; ICH, intracerebral hemorrhage; SVD, small vessel disease.

verse (Figure 3), and they can be categorized according to the locational distribution of SNILs. For local lesion recurrence, several mechanisms are plausible, including 1) fragmentation of the initial embolus during the process of recanalization and reperfusion; ${ }^{6} 2$ ) recurrent ischemic events (recurrent emboli) within the same perfusion deficit caused by intrinsic atherosclerosis; ${ }^{6}$ and 3) recurrent ischemic events due to prolonged hypoperfusion. ${ }^{11}$ Meanwhile, for distant lesion recurrence, recurrent embolic events arising from a proximal source, such as the heart or activated atherosclerotic plaque located outside of the initial culprit vessels, may be important. Accordingly, atrial fibrillation and the presence of microembolic signals demonstrated by transcranial Doppler ultrasonography are reportedly associated with the advent of early SNILs. ${ }^{20}$ Of note, there are also other players acting as common pathogenic denominators. For example, induced inflammatory response after stroke and/or hypercoagulability, which sustainably activate plaque, may contribute to the development of both local and distant SNILs. ${ }^{6}$

\section{Early and late SNILs and clinical vascular events}

Early SNILs at 5 days have been shown to be independently associated with late SNILs at 30 or 90 days, suggesting a continued risk of recurrent ischemic lesions in the weeks following the index stroke. ${ }^{7}$ Atheroma, which is an acute-on-chronic disease causing recurrent episodes of thromboembolism before the stabilization of an ulcerated plaque, has been suggested as the culprit mechanism for this prolonged stroke-prone state. ${ }^{26}$

As for clinical vascular events, late SNILs independently predict recurrent ischemic strokes. Early SNILs, together with late SNILs, can predict the combined clinical endpoints of recurrent ischemic stroke, transient ischemic attack (TIA), and vascular death. ${ }^{8}$ The superiority of late SNILs to early SNILs in predicting subsequent clinical vascular events may be explained by the different pathogeneses of the two types of SNILs. Early
SNILs, which include local lesion recurrence, may result from progression of the initial ischemic event. On the contrary, late SNILs, of which the major form is distant lesion recurrence, may accurately reflect the risk of future recurrent ischemic events. $^{8}$

\section{Minor stroke and TIA}

It has been considered that a previous TIA or minor stroke confers a greater risk for recurrent stroke. ${ }^{27,28}$ Accordingly, SNILs can also appear after TIA and minor stroke (National Institutes of Health Stroke Scale score <3-6). ${ }^{29-31}$ The incidences of SNILs in this population have been reported as $18 \%$ at 7 days, and $7 \%-22 \%$ at 30 or 90 days, both of which are lower than those of SNILs after acute ischemic stroke (Table 1). This difference may be attributable to the fact that TIA and minor strokes are less likely to recur compared to acute ischemic strokes. ${ }^{29}$

Further, LAA and cardioembolism are most likely to be associated with SNILs in patients with TIA and minor strokes. ${ }^{19,29}$ Among the MRI parameters, the baseline DWI lesion volume and perfusion deficits have been shown to significantly associate with the advent of SNILs. ${ }^{30,31}$

\section{SNILs after acute intracerebral hemorrhage (ICH)}

Since ischemic and hemorrhagic strokes are distinctive diseases, stroke patients usually present with one of the two. However, although rare, symptomatic acute ischemic and hemorrhagic stroke can occur simultaneously or shortly after one another. ${ }^{32-34}$ Moreover, both types of stroke share common risk factors such as old age, hypertension, and high alcohol intake. ${ }^{35,36}$ In this regard, there have been efforts to investigate SNILs after acute ICH using DWI.

\section{Definition, incidence, and baseline characteristics}

SNILs after acute ICH are defined as any hyperintense lesions on the subsequent DWI that are distinct from hemorrhage and the area of perihematomal edema (Figure 4). ${ }^{37-43}$ SNILs may appear as early as within 5 days; follow-up MRI is usually performed within 14 days, but may be performed up to 3 months after the index hemorrhage (Table 2). The reported prevalence rates of SNILs after acute ICH are $11.1 \%-41.1 \%$ within 14 -days, $22.9 \%-26.5 \%$ at 1 month, and $13.2 \%$ at 3 months. The lesion size of SNILs after ICH also tends to be small; more than $70 \%$ of lesions have a diameter less than 10 $\mathrm{mm} \cdot{ }^{37,38,42}$ Further, patients with cerebral amyloid angiopathy are more likely to develop SNILs at 3 months after ICH, and have a more severe hemorrhagic burden (i.e., more frequent microbleeds, multiple ICHs, and intraventricular hemorrhage) 
Table 2. New ischemic lesions after acute intracerebral hemorrhage

\begin{tabular}{|c|c|c|c|c|c|}
\hline & Time of follow-up MRI & No. of patients & Incidence of SNILS & Location & Associated factors with new ischemic lesions* \\
\hline Prabhakaran ${ }^{37}$ & Within 28 days & 118 & $27(22.9 \%)$ & Subcortical $(70.4 \%)$ & $\begin{array}{l}\text { Prior ischemic stroke, craniotomy, delta MAP } \\
\text { lowering } \geq 40 \% \text {, hypertensive etiology }\end{array}$ \\
\hline Gregoire $^{38}$ & Within 3 months & 114 & $\begin{array}{r}15(13.2 \%) \\
\text { CAA: } 9 / 39(23.1 \%) \\
\text { Others: } 6 / 75(8.0 \%)\end{array}$ & Mainly cortical & $\begin{array}{l}\text { WM change score } \\
\text { Presence of lobar MBs }\end{array}$ \\
\hline Menon $^{39}$ & $\begin{array}{l}\text { Baseline } \\
\text { (median } 2 \text { days) } \\
\text { and } 1 \text { month }\end{array}$ & 138 & $\begin{array}{c}\text { Base: } 42 / 119(35.2 \%) \\
1 \text { month: } 30 / 113(26.5 \%)^{\dagger}\end{array}$ & $\begin{array}{l}\text { Base: } 44 \% \text { in lobar } \\
1 \text { month: } 13 \% \text { in lobar }\end{array}$ & $\begin{array}{l}\text { Baseline: Hematoma volume, baseline IVH, baseline } \\
\text { MBs, and delta MAP } \\
1 \text { month: Any prior stroke, baseline microbleeds }\end{array}$ \\
\hline $\operatorname{Garg}^{40}$ & Within 10 days & 95 & $39(41.1 \%)$ & Not available & \\
\hline Kang $^{41}$ & Within 5 days & $97^{\ddagger}$ & $26(26.8 \%)$ & $\begin{array}{l}\text { Subcortical WM or } \\
\text { brainstem (75.5\%) }\end{array}$ & $\begin{array}{l}\text { Baseline MBs }>2 \text {, moderate-to-severe WM leukoar- } \\
\text { aiosis }\end{array}$ \\
\hline Tsai ${ }^{42}$ & $\begin{array}{c}2 \text { weeks (DWI) } \\
3 \text { months (T2W/FLAIR) }\end{array}$ & 153 & 2 weeks: $17 / 153(11.1 \%)^{\S}$ & Cortical (64.7\%) & \\
\hline Gioia $^{43}$ & Within 14 days & 117 & $17(14.5 \%)$ & $\begin{array}{c}\text { Cortical }(50.0 \%) \\
\text { Subcortical }(47.6 \%)\end{array}$ & \\
\hline
\end{tabular}

"Only variables determined as significant by multivariable analysis; ${ }^{\dagger}$ Of the $40 \mathrm{DWl}$ lesions at 1 month, $33(82.5 \%)$ were new compared to in the baseline DWl; ${ }^{\ddagger}$ Only patients with hypertensive intracranial hemorrhage; ${ }^{\S}$ Of the $20 \mathrm{DWI}$ lesions, 13 (52.0\%) were not found on the follow-up T2-weighted or FLAIR images.

CAA, cerebral amyloid angiopathy; DWI, diffusion-weighted imaging; FLAIR, fluid attenuated inversion recovery; IVH, intraventricular hemorrhage; MAP, mean arterial pressure; MBs, microbleeds; MRI, magnetic resonance imaging; SNILs, silent new ischemic lesions; T2W, T2 weighted; WM, white matter.

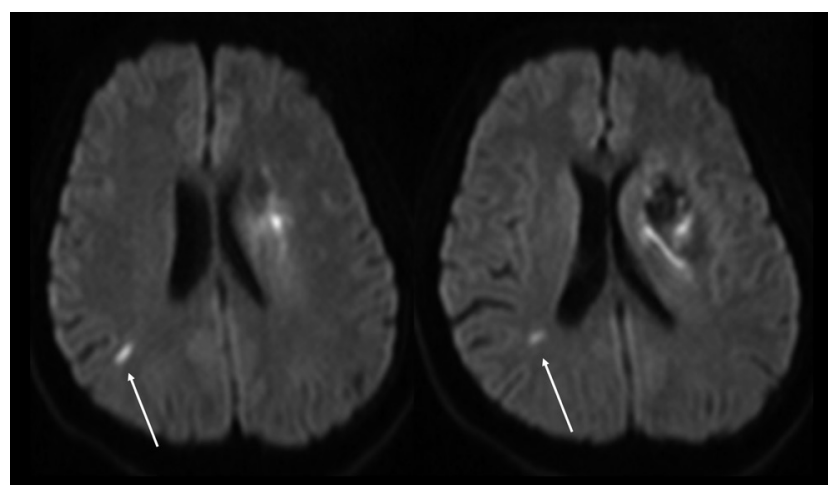

Figure 4. Early silent new ischemic lesions (arrows) coexisting with acute intracerebral hemorrhage in the left basal ganglion. Magnetic resonance imaging was performed 2 days after symptom onset.

compared to those with other primary ICHs. ${ }^{38}$ The main locations of SNILs have been reported to vary. Notably, however, patients with hypertensive ICH develop SNILs mainly in the subcortical white matter or brainstem. ${ }^{41}$

The natural course of SNILs after acute ICH is dynamic. When comparing baseline (median, 2 days) and 1-month DWIs after acute primary ICH, more than $80 \%$ of SNILs on the follow-up DWI were not present at baseline, demonstrating that SNILs develop through an ongoing process during the acute phase. ${ }^{39}$ Meanwhile, half of all SNILs on the 2-week DWI reportedly do not remain on the subsequent 3-month MRI, suggesting that not all early SNILs after acute ICH indicate permanent tissue injury. ${ }^{42}$

\section{Associated factors and mechanisms}

Several risk and clinical factors have been reported to be asso- ciated with SNILs after acute ICH, although the results are inconsistent and even contradictory among studies.

Microbleeds and leukoaraiosis have been independently and consistently associated with the occurrence of SNILs after acute ICH. ${ }^{38,39,41}$ Microbleeds are an imaging marker of bleedingprone microangiopathies, ${ }^{44}$ while leukoaraiosis represents chronic hypoperfusion in the distal deep and arteriolar territories. ${ }^{45}$ Remarkably, microbleeds and leukoaraiosis are strongly correlated, ${ }^{46}$ and, when combined, they represent small vessel pathology. ${ }^{47}$ Chronic changes by longstanding hypertension in the form of microaneurysm, lipohyalinosis, and fibrinoid degeneration develop in the deep small vessels and are associated with both hypertensive ICH and ischemic lacunes. Thus, an active small-vessel angiopathic process induced by hemorrhagic insults may underlie the advent of SNILs. ${ }^{41}$

History of ischemic stroke has been suggested as an independent predictor of SNILs after acute ICH. ${ }^{37,39}$ Moreover, this has been regarded as a surrogate marker of perforator disease, where relative hypoperfusion can result in ischemia in a single or multiple perforators. ${ }^{37}$ However, the association between prior ischemic stroke and SNILs after acute ICH was denied in other studies. ${ }^{40,41}$

Another suggested risk factor of SNILs after acute ICH is decreased blood pressure during the acute phase. ${ }^{37,39,40}$ In chronic hypertension, the curve of cerebral autoregulation is shifted to the right, and after acute brain injury, autoregulation may be abolished so that cerebral blood flow changes linearly according to cerebral perfusion pressure. ${ }^{48}$ As elevations in intracranial pressure due to acute $\mathrm{ICH}$ would result in cerebral perfusion pressure decreases, aggressive blood pressure lowering therapy beyond the 
lower limits of cerebral autoregulation might induce cerebral ischemia in ICH patients with chronic hypertension. ${ }^{37}$ However, of note, the perihematoma region is known to be unaccompanied by hypoperfusion or ischemia, and rather shows benign oligemia. ${ }^{49-53}$ Moreover, the relationship between reduction of blood pressure and the advent of SNILs was not reproduced in some studies. ${ }^{41,43}$ Thus, it remains controversial whether decreased blood pressure is the culprit behind the occurrence of SNILs.

Large ICH volume and subsequent craniotomy have been suggested to be associated with SNIL development. ${ }^{37,39}$ Elevated intracranial pressure in patients with large volume of $\mathrm{ICH}$ may have a negative impact on the cerebral perfusion pressure and secondarily on the cerebral blood flow. In addition, brain shifts from large hematomas may directly compress neighboring vascular structures, contributing to tissue infarction. However, both large ICH volume and craniotomy did not show any significant association with SNILs in other studies. ${ }^{40,41}$

\section{Clinical implication of SNILS \\ Predictor of prognosis and future events}

SNILs on DWI after acute ischemic or hemorrhagic stroke can be used to predict future clinical events and prognosis. DWI can be considered as a crystal ball, while SNILs are an omen.

Regarding SNILs after acute ischemic stroke, both early SNILs at 5 days and late SNILs in the subacute phase up to 90 days have been shown to be independent predictors of subsequent clinical vascular events such as recurrent ischemic stroke, TIA, and vascular death during a median follow-up of 1.6 years. ${ }^{7,8}$ Thus, patients with SNILs over the early weeks after an index stroke should be considered optimal candidates for early aggressive stroke prevention therapy. In addition, SNILs may provide a useful surrogate endpoint in clinical trials evaluating stroke prevention therapies, with the reduction in the lesion recurrence rate upon pharmacologic intervention over the initial weeks used as a surrogate for reduction in clinical stroke recurrence over the following years. Clinical trials to test the efficacy of therapeutic interventions usually take many years to recruit for and complete. An MRI surrogate endpoint of recurrent stroke, which would allow substantially fewer patients and shorter follow-up period, would result in enormous savings of cost and time in evaluating the preventive therapies. However, currently, only data from single-center and retrospective studies are available. Thus, future prospective randomized controlled trials testing the effect of a stroke prevention therapy on SNILs and clinical stroke recurrence in the long-term are required.

SNILs after acute ICH also have prognostic value; in one study, they were independently associated with dependence or death of patients at 3 months, ${ }^{40}$ and in another, with the com- posite of clinical cerebrovascular endpoints (i.e., ischemic stroke, $\mathrm{ICH}$, and vascular death) during a median follow-up of 3.5 years. ${ }^{41}$ These findings warrant special care in $\mathrm{ICH}$ patients with SNILs to reduce the risk of cerebrovascular events in the future. As SNILs after acute ICH predict not only hemorrhagic but also ischemic strokes during the follow-up, antiplatelets associated with lower risks of bleeding complications may be considered in this group of patients to prevent subsequent cerebrovascular events. The efficacy of antiplatelets in these patients should be proven, and the safe interval from ICH onset to initiation of antiplatelet administration is also to be determined. In addition, the optimal level of blood pressure should be delicately set to prevent SNILs as well as ICH progression.

\section{Cognitive impairment}

Silent ischemic lesions on MRI have been associated with cognitive dysfunction or dementia in asymptomatic populations. ${ }^{5467}$ The size and location of ischemic lesions may be important for such associations. In order to remain silent, the ischemic lesions should be small and located in appropriate areas such as the frontal lobe, not causing focal neurologic deficits. However, as silent lesions accumulate in the affected area, the increased ischemic burden may contribute to impairment of cognitive function and to difficulties in mental flexibility, language, and memories. ${ }^{68-74}$ Besides the location, the extent of silent ischemic lesions is also important for the development of cognitive dysfunction. The degree of the lesions on MRI has shown a positive correlation with the severity of cognitive impairment. $^{65,75-77}$

SNILs after acute ischemic or hemorrhagic strokes are small and asymptomatic initially; further, they can occur virtually anywhere according to the location of the index stroke. Thus, their accumulation may also contribute to cognitive decline during the follow-up. Moreover, considering that many patients with a history of ischemic or hemorrhagic strokes are also accompanied by many vascular risk factors, which are known to increase the risk of dementia, ${ }^{78}$ special attention should be paid to the risk of cognitive impairment in these patients.

\section{SNMs}

Microbleeds refer to small, round, dark-signal lesions detected by $\mathrm{T} 2{ }^{*}$-weighted GRE or susceptibility-weighted imaging. ${ }^{79-81}$ They are known to be manifestations of focal extravascular leakage of blood components, representing old microhemorrhages, but rarely cause overt symptoms. ${ }^{82}$ Although not studied as much as SNILs, SNMs are also known to appear after acute ischemic or hemorrhagic stroke. 


\section{SNMs after acute ischemic stroke}

Microbleeds are frequently found in ischemic stroke patients, at varying rates (35\%-71\%). ${ }^{82-84}$ In addition, they are more common in patients with recurrent strokes than in those experiencing a first-ever stroke, ${ }^{85}$ whereas they are rarely found in TIA patients. ${ }^{86}$ These findings suggest that ischemic stroke may trigger the occurrence of microbleeds.

\section{Definition and incidence}

Microbleeds are defined as unambiguous homogeneous, round, signal-loss lesions with diameters up to 5-10 $\mathrm{mm}$ and with blooming artifacts, as determined by GRE. ${ }^{87-89}$ In one previous study, within 24 hours, approximately $30 \%$ of patients with acute ischemic stroke showed a number of concurrent microbleeds (median 2, range 1-33) in their brains. ${ }^{87}$ During the acute phase, another $13 \%$ of patients developed SNMs (median 1, range 1-5) on the 7-day GRE, while 3\% of patients lost their baseline microbleeds. ${ }^{87}$ As for the locations, about half of all microbleeds were detected in the deep hemisphere; at baseline, $32 \%$ were located in the lobar location while $30 \%$ were in the deep location, whereas on follow-up GRE, 52\% of SNMs were found in the lobar location. ${ }^{87}$

The long-term fate of SNMs is also dynamic, as the appearance and disappearance of SNMs can occur years after the index acute ischemic stroke. ${ }^{88,89}$ In one study, during a mean follow-up of 27 months, $38 \%$ of acute ischemic stroke patients had SNMs on their subsequent GRE, with the total number of microbleeds increasing by about 1.5 -fold ${ }^{88}$ Among the patients with baseline microbleeds, 54\% developed SNMs during their follow-up, showing a generally increasing trend in the number of microbleeds, although some of these lesions disappeared in $15 \%$ of those patients. In fact, de novo SNMs were detected even on the 5-year follow-up GRE in 30\% of patients with index ischemic strokes. ${ }^{89}$

\section{Associated factors and mechanism}

The presence and number of baseline microbleeds are consistently associated with the advent of SNMs on follow-up GREs, regardless of the time from baseline ( 5 days to 5 years) ${ }^{87-89}$ Moreover, they have been shown to be positively related with the annual rate at which SNMs develop. ${ }^{88}$ The multiplicity of microbleeds at the initial clinical presentation may imply that they occurred through various time points around the onset of stroke, suggesting a prolonged risk of SNMs in particular stroke patients. ${ }^{87}$ The number of baseline hemorrhages may be a marker of the severity and aggressiveness of the underlying vascular disease.$^{87}$ In addition, the above findings are in line with findings of other studies indicating that the total number of baseline microbleeds can predict the risk of future hemorrhages. ${ }^{90-92}$ The burden of small vessel disease such as leukoaraiosis or lacunar infarctions is an independent predictor of the development of SNMs in ischemic stroke patients. ${ }^{87,88}$ The small vessel disease severity is well known to correlate with the number of microbleeds. ${ }^{46}$ As microbleeds arise from microangiopathic changes after chronic hypertension, the number of microbleeds may hence reflect bleeding-prone and small vessel disease-prone microangiopathy. ${ }^{93}$

The level of low-density lipoprotein cholesterol is inversely associated with SNMs. ${ }^{88}$ Low concentrations of serum cholesterol are related with the risk of microbleeds, suggesting an antagonizing role of cholesterol in the pathogenesis of microbleeds. ${ }^{94,95}$ Given that microbleeds is characterized by hemosiderin pigment accumulations in macrophages adjacent to the ruptured atherosclerotic microvessels, the low-density lipoprotein cholesterol level may be related to either changes of microaneurysms $s^{94,96}$ or the clearance of hemosiderin-containing microglia. ${ }^{88}$

Increased body temperature has also been reported to be associated with the presence of SNMs within 7 days. ${ }^{87}$ High temperature is known to induce blood-brain barrier disruption after ischemic stroke. ${ }^{97}$ As endothelial activation and damage, with subsequent breakdown of the blood-brain barrier, are key features in cerebral small vessel diseases, high temperature may also contribute to the disease process. ${ }^{98}$

However, a caution in interpretation is needed for the abovementioned studies, since spatial registration of baseline and follow-up GRE images have not been performed in any published studies. $^{82}$

\section{SNMs after acute ICH}

The coexistence of SNMs in patients with ICH has consistently been reported as more frequent than that in ischemic stroke patients, reaching 50\%-80\%. ${ }^{91,93,99-101}$ However, only limited studies have evaluated whether SNMs occur following acute ICH by performing serial GRE studies.

In one study, SNMs occurred in 9 of 24 patients (38\%) with cerebral amyloid angiopathy and previous lobar hemorrhage during the 1.5 -year follow-up period. ${ }^{102}$ In another study, in hypertensive ICH patients, SNMs were found in 19 of 63 patients (30\%) after a median follow-up of 23 months. ${ }^{90}$

\section{Clinical implication of SNMs}

Since its discovery, the clinical significance of microbleeds has been actively investigated. The presence of microbleeds is associated with the future advent of hemorrhagic stroke after index ischemic or hemorrhagic stroke, especially in patients with se- 
vere white matter ischemic lesions. ${ }^{90,103,104}$ In addition, microbleeds have been associated with larger volume of $\mathrm{ICH}^{105,106}$ and hemorrhagic transformation after ischemic stroke, ${ }^{107-109}$ although the latter has been denied by other studies. ${ }^{110-114}$ Recurrent ischemic stroke also has been linked to the presence of microbleeds, ${ }^{115}$ while the association turned out to be only modest when compared to that of hemorrhagic stroke in a systematic review. ${ }^{103}$ Lastly, microbleeds are associated with cognitive dysfunction, especially frontal-executive impairment. ${ }^{16,117}$

Based on the above-mentioned data, SNMs appearing after acute cerebrovascular events may be suggestive of future risk of hemorrhagic stroke and cognitive dysfunction, similar to SNILs. However, there is currently no direct evidence that SNMs can predict these events in the early phase after acute events. Thus, SNMs should be examined in more detail in terms of their clinical implications, and future studies are warranted.

\section{References}

1. Derdeyn CP. Diffusion-weighted imaging as a surrogate marker for stroke as a complication of cerebrovascular procedures and devices. AJNR Am J Neuroradiol 2001;22:1234-1235.

2. Sacco RL, Foulkes MA, Mohr JP, Wolf PA, Hier DB, Price TR. Determinants of early recurrence of cerebral infarction. The Stroke Data Bank. Stroke 1989;20:983-989.

3. Sacco RL, Shi T, Zamanillo MC, Kargman DE. Predictors of mortality and recurrence after hospitalized cerebral infarction in an urban community: the Northern Manhattan Stroke Study. Neurology 1994;44:626-634.

4. Warach S, Gaa J, Siewert B, Wielopolski P, Edelman RR. Acute human stroke studied by whole brain echo planar diffusionweighted magnetic resonance imaging. Ann Neurol 1995;37: 231-241.

5. Roh JK, Kang DW, Lee SH, Yoon BW, Chang KH. Significance of acute multiple brain infarction on diffusion-weighted imaging. Stroke 2000;31:688-694.

6. Kang DW, Latour LL, Chalela JA, Dambrosia J, Warach S. Early ischemic lesion recurrence within a week after acute ischemic stroke. Ann Neurol 2003;54:66-74.

7. Kang DW, Latour LL, Chalela JA, Dambrosia JA, Warach S. Early and late recurrence of ischemic lesion on MRI: evidence for a prolonged stroke-prone state? Neurology 2004;63:22612265.

8. Kang DW, Lattimore SU, Latour LL, Warach S. Silent ischemic lesion recurrence on magnetic resonance imaging predicts subsequent clinical vascular events. Arch Neurol 2006;63:17301733.

9. Nolte $\mathrm{CH}$, Albach FN, Heuschmann PU, Brunecker P,
Villringer K, Endres M, et al. Silent new DWI lesions within the first week after stroke. Cerebrovasc Dis 2012;33:248-254.

10. Kang DW, Yoo SH, Chun S, Kwon KY, Kwon SU, Koh JY, et al. Inflammatory and hemostatic biomarkers associated with early recurrent ischemic lesions in acute ischemic stroke. Stroke 2009;40:1653-1658.

11. Jeon SB, Song HS, Kim BJ, Kim HJ, Kang DW, Kim JS, et al. Biochemical aspirin resistance and recurrent lesions in patients with acute ischemic stroke. Eur Neurol 2010;64:51-57.

12. Bang OY, Kim GM, Chung CS, Kim SJ, Kim KH, Jeon P, et al. Differential pathophysiological mechanisms of stroke evolution between new lesions and lesion growth: perfusion-weighted imaging study. Cerebrovasc Dis 2010;29:328-335.

13. Kang DW, Kwon SU, Yoo SH, Kwon KY, Choi CG, Kim SJ, et al. Early recurrent ischemic lesions on diffusion-weighted imaging in symptomatic intracranial atherosclerosis. Arch Neurol 2007;64:50-54.

14. Jeong TD, Kim SM, Kim HJ, Lee W, Kwon SU, Min WK, et al. CYP2C19 genotype and early ischemic lesion recurrence in stroke patients treated with clopidogrel. J Stroke Cerebrovasc Dis 2015;24:440-446.

15. Petty GW, Brown RD Jr, Whisnant JP, Sicks JD, O’Fallon WM, Wiebers DO. Survival and recurrence after first cerebral infarction: a population-based study in Rochester, Minnesota, 1975 through 1989. Neurology 1998;50:208-216.

16. Berge E, Abdelnoor M, Nakstad PH, Sandset PM. Low molecular-weight heparin versus aspirin in patients with acute ischaemic stroke and atrial fibrillation: a double-blind randomised study. HAEST Study Group. Heparin in Acute Embolic Stroke Trial. Lancet 2000;355:1205-1210.

17. The Publications Committee for the Trial of ORG 10172 in Acute Stroke Treatment (TOAST) Investigators. Low molecular weight heparinoid, ORG 10172 (danaparoid), and outcome after acute ischemic stroke: a randomized controlled trial. JAMA 1998;279:1265-1272.

18. International Stroke Trial Collaborative Group. The International Stroke Trial (IST): a randomised trial of aspirin, subcutaneous heparin, both, or neither among 19435 patients with acute ischaemic stroke. Lancet 1997;349:1569-1581.

19. Sylaja PN, Coutts SB, Subramaniam S, Hill MD, Eliasziw M, Demchuk AM. Acute ischemic lesions of varying ages predict risk of ischemic events in stroke/TIA patients. Neurology 2007;68:415-419.

20. Iguchi Y, Kimura K, Kobayashi K, Ueno Y, Shibazaki K, Inoue T. Microembolic signals at 48 hours after stroke onset contribute to new ischaemia within a week. J Neurol Neurosurg Psychiatry 2008;79:253-259.

21. Arenillas JF, Molina CA, Montaner J, Abilleira S, Gonzalez- 
Sanchez MA, Alvarez-Sabin J. Progression and clinical recurrence of symptomatic middle cerebral artery stenosis: a longterm follow-up transcranial Doppler ultrasound study. Stroke 2001;32:2898-2904.

22. AbuRahma AF, Wulu JT Jr, Crotty B. Carotid plaque ultrasonic heterogeneity and severity of stenosis. Stroke 2002;33:17721775 .

23. Chimowitz MI, Lynn MJ, Howlett-Smith H, Stern BJ, Hertzberg VS, Frankel MR, et al. Comparison of warfarin and aspirin for symptomatic intracranial arterial stenosis. $N$ Engl J Med 2005;352:1305-1316.

24. Barber M, Langhorne P, Rumley A, Lowe GD, Stott DJ. Hemostatic function and progressing ischemic stroke: $\mathrm{D}$-dimer predicts early clinical progression. Stroke 2004;35:1421-1425.

25. Robson SC, Shephard EG, Kirsch RE. Fibrin degradation product $\mathrm{D}$-dimer induces the synthesis and release of biologically active IL-1 beta, IL-6 and plasminogen activator inhibitors from monocytes in vitro. Br J Haematol 1994;86:322-326.

26. Hankey GJ, Jamrozik K, Broadhurst RJ, Forbes S, Burvill PW, Anderson CS, et al. Long-term risk of first recurrent stroke in the Perth Community Stroke Study. Stroke 1998;29:24912500 .

27. Whisnant JP, Matsumoto N, Elveback LR. Transient cerebral ischemic attacks in a community. Rochester, Minnesota, 1955 through 1969. Mayo Clin Proc 1973;48:194-198.

28. Friedman GD, Wilson WS, Mosier JM, Colandrea MA, Nichaman MZ. Transient ischemic attacks in a community. JAMA 1969;210:1428-1434.

29. Coutts SB, Hill MD, Simon JE, Sohn CH, Scott JN, Demchuk AM. Silent ischemia in minor stroke and TIA patients identified on MR imaging. Neurology 2005;65:513-517.

30. Asdaghi N, Hameed B, Saini M, Jeerakathil T, Emery D, Butcher K. Acute perfusion and diffusion abnormalities predict early new MRI lesions 1 week after minor stroke and transient ischemic attack. Stroke 2011;42:2191-2195.

31. Nah HW, Kwon SU, Kang DW, Lee DH, Kim JS. Diagnostic and prognostic value of multimodal MRI in transient ischemic attack. Int J Stroke 2014;9:895-901.

32. Guzzini F, Conti A, Esposito F. Simultaneous ischemic and hemorrhagic lesions of the brain detected by CT scan in a patient with thrombotic thrombocytopenic purpura. Haematologica 1998;83:280.

33. Kim CH, Kim JS. Development of cerebral infarction shortly after intracerebral hemorrhage. Eur Neurol 2007;57:145-149.

34. Toyoda K, Kumai Y, Fujii K, Ando T, Ibayashi S. Simultaneous onset of haemorrhagic and ischaemic strokes in a haemodialysis patient. J Neurol Neurosurg Psychiatry 2002;72:673674.
35. Ariesen MJ, Claus SP, Rinkel GJ, Algra A. Risk factors for intracerebral hemorrhage in the general population: a systematic review. Stroke 2003;34:2060-2065.

36. Allen CL, Bayraktutan U. Risk factors for ischaemic stroke. Int J Stroke 2008;3:105-116.

37. Prabhakaran S, Gupta R, Ouyang B, John S, Temes RE, Mohammad $Y$, et al. Acute brain infarcts after spontaneous intracerebral hemorrhage: a diffusion-weighted imaging study. Stroke 2010;41:89-94.

38. Gregoire SM, Charidimou A, Gadapa N, Dolan E, Antoun N, Peeters A, et al. Acute ischaemic brain lesions in intracerebral haemorrhage: multicentre cross-sectional magnetic resonance imaging study. Brain 2011;134:2376-2386.

39. Menon RS, Burgess RE, Wing JJ, Gibbons MC, Shara NM, Fernandez S, et al. Predictors of highly prevalent brain ischemia in intracerebral hemorrhage. Ann Neurol 2012;71:199205.

40. Garg RK, Liebling SM, Maas MB, Nemeth AJ, Russell EJ, Naidech AM. Blood pressure reduction, decreased diffusion on MRI, and outcomes after intracerebral hemorrhage. Stroke 2012;43:67-71.

41. Kang DW, Han MK, Kim HJ, Yun SC, Jeon SB, Bae HJ, et al. New ischemic lesions coexisting with acute intracerebral hemorrhage. Neurology 2012;79:848-855.

42. Tsai YH, Lee MH, Weng HH, Chang SW, Yang JT, Huang YC. Fate of diffusion restricted lesions in acute intracerebral hemorrhage. PLoS One 2014;9:e105970.

43. Gioia LC, Kate M, Choi V, Sivakumar L, Jeerakathil T, Kosior $\mathrm{J}$, et al. Ischemia in intracerebral hemorrhage is associated with leukoaraiosis and hematoma volume, not blood pressure reduction. Stroke 2015;46:1541-1547.

44. Roob G, Fazekas F. Magnetic resonance imaging of cerebral microbleeds. Curr Opin Neurol 2000;13:69-73.

45. Inzitari D. Leukoaraiosis: an independent risk factor for stroke? Stroke 2003;34:2067-2071.

46. Lee SH, Bae HJ, Ko SB, Kim H, Yoon BW, Roh JK. Comparative analysis of the spatial distribution and severity of cerebral microbleeds and old lacunes. J Neurol Neurosurg Psychiatry 2004;75:423-427.

47. Staals J, Makin SD, Doubal FN, Dennis MS, Wardlaw JM. Stroke subtype, vascular risk factors, and total MRI brain small-vessel disease burden. Neurology 2014;83:1228-1234.

48. Paulson OB, Waldemar G, Schmidt JF, Strandgaard S. Cerebral circulation under normal and pathologic conditions. Am J Cardiol 1989;63:2c-5c.

49. Powers WJ, Zazulia AR, Videen TO, Adams RE, Yundt KD, Aiyagari $\mathrm{V}$, et al. Autoregulation of cerebral blood flow surrounding acute ( 6 to 22 hours) intracerebral hemorrhage. Neurology 
2001;57:18-24.

50. Zazulia AR, Diringer MN, Videen TO, Adams RE, Yundt K, Aiyagari $\mathrm{V}$, et al. Hypoperfusion without ischemia surrounding acute intracerebral hemorrhage. J Cereb Blood Flow Metab 2001;21:804-810.

51. Mayer SA, Lignelli A, Fink ME, Kessler DB, Thomas CE, Swarup $\mathrm{R}$, et al. Perilesional blood flow and edema formation in acute intracerebral hemorrhage: a SPECT study. Stroke 1998; 29:1791-1798.

52. Kidwell CS, Saver JL, Mattiello J, Warach S, Liebeskind DS, Starkman S, et al. Diffusion-perfusion MR evaluation of perihematomal injury in hyperacute intracerebral hemorrhage. Neurology 2001;57:1611-1617.

53. Herweh C, Juttler E, Schellinger PD, Klotz E, Jenetzky E, Orakcioglu B, et al. Evidence against a perihemorrhagic penumbra provided by perfusion computed tomography. Stroke 2007; 38:2941-2947.

54. Hofman A, de Jong PT, van Duijn CM, Breteler MM. Epidemiology of neurological diseases in elderly people: what did we learn from the Rotterdam Study? Lancet Neurol 2006;5:545550.

55. Longstreth WT Jr, Dulberg C, Manolio TA, Lewis MR, Beauchamp NJ Jr, O’Leary D, et al. Incidence, manifestations, and predictors of brain infarcts defined by serial cranial magnetic resonance imaging in the elderly: the Cardiovascular Health Study. Stroke 2002;33:2376-2382.

56. van der Flier WM, van Straaten EC, Barkhof F, Verdelho A, Madureira S, Pantoni L, et al. Small vessel disease and general cognitive function in nondisabled elderly: the LADIS study. Stroke 2005;36:2116-2120.

57. Mosley TH Jr, Knopman DS, Catellier DJ, Bryan N, Hutchinson RG, Grothues CA, et al. Cerebral MRI findings and cognitive functioning: the Atherosclerosis Risk in Communities study. Neurology 2005;64:2056-2062.

58. Soderlund H, Nilsson LG, Berger K, Breteler MM, Dufouil C, Fuhrer R, et al. Cerebral changes on MRI and cognitive function: the CASCADE study. Neurobiol Aging 2006;27:16-23.

59. Atwood LD, Wolf PA, Heard-Costa NL, Massaro JM, Beiser A, D’Agostino RB, et al. Genetic variation in white matter hyperintensity volume in the Framingham Study. Stroke 2004;35:16091613.

60. Price TR, Manolio TA, Kronmal RA, Kittner SJ, Yue NC, Robbins J, et al. Silent brain infarction on magnetic resonance imaging and neurological abnormalities in community-dwelling older adults. The Cardiovascular Health Study. CHS Collaborative Research Group. Stroke 1997;28:1158-1164.

61. Schmidt R, Ropele S, Enzinger C, Petrovic K, Smith S, Schmidt $\mathrm{H}$, et al. White matter lesion progression, brain atrophy, and cognitive decline: the Austrian stroke prevention study. Ann Neurol 2005;58:610-616.

62. Vermeer SE, Longstreth WT Jr, Koudstaal PJ. Silent brain infarcts: a systematic review. Lancet Neurol 2007;6:611-619.

63. Pathological correlates of late-onset dementia in a multicentre, community-based population in England and Wales. Neuropathology Group of the Medical Research Council Cognitive Function and Ageing Study (MRC CFAS). Lancet 2001;357: 169-175.

64. Manschot SM, Brands AM, van der Grond J, Kessels RP, Algra A, Kappelle LJ, et al. Brain magnetic resonance imaging correlates of impaired cognition in patients with type 2 diabetes. Diabetes 2006;55:1106-1113.

65. Vermeer SE, Prins ND, den Heijer T, Hofman A, Koudstaal PJ, Breteler MM. Silent brain infarcts and the risk of dementia and cognitive decline. N Engl J Med 2003;348:1215-1222.

66. Gouw AA, van der Flier WM, Fazekas F, van Straaten EC, Pantoni L, Poggesi A, et al. Progression of white matter hyperintensities and incidence of new lacunes over a 3-year period: the Leukoaraiosis and Disability study. Stroke 2008;39:14141420.

67. Norrving B. Long-term prognosis after lacunar infarction. Lancet Neurol 2003;2:238-245.

68. Sun X, Lindsay J, Monsein LH, Hill PC, Corso PJ. Silent brain injury after cardiac surgery: a review: cognitive dysfunction and magnetic resonance imaging diffusion-weighted imaging findings. J Am Coll Cardiol 2012;60:791-797.

69. Bendszus M, Stoll G. Silent cerebral ischaemia: hidden fingerprints of invasive medical procedures. Lancet Neurol 2006;5: 364-372.

70. Ishii N, Nishihara Y, Imamura T. Why do frontal lobe symptoms predominate in vascular dementia with lacunes? Neurology 1986;36:340-345.

71. Wolfe N, Linn R, Babikian VL, Knoefel JE, Albert ML. Frontal systems impairment following multiple lacunar infarcts. Arch Neurol 1990;47:129-132.

72. Reed BR, Eberling JL, Mungas D, Weiner M, Kramer JH, Jagust WJ. Effects of white matter lesions and lacunes on cortical function. Arch Neurol 2004;61:1545-1550.

73. Vermeer SE, Den Heijer T, Koudstaal PJ, Oudkerk M, Hofman A, Breteler MM. Incidence and risk factors of silent brain infarcts in the population-based Rotterdam Scan Study. Stroke 2003;34:392-396.

74. Mungas D, Harvey D, Reed BR, Jagust WJ, DeCarli C, Beckett $\mathrm{L}$, et al. Longitudinal volumetric MRI change and rate of cognitive decline. Neurology 2005;65:565-571.

75. Vermeer SE, Koudstaal PJ, Oudkerk M, Hofman A, Breteler MM. Prevalence and risk factors of silent brain infarcts in the 
population-based Rotterdam Scan Study. Stroke 2002;33:2125.

76. De Groot JC, De Leeuw FE, Oudkerk M, Van Gijn J, Hofman A, Jolles J, et al. Periventricular cerebral white matter lesions predict rate of cognitive decline. Ann Neurol 2002;52:335-341.

77. Wentzel C, Rockwood K, MacKnight C, Hachinski V, Hogan DB, Feldman H, et al. Progression of impairment in patients with vascular cognitive impairment without dementia. Neurology 2001;57:714-716.

78. Norton S, Matthews FE, Barnes DE, Yaffe K, Brayne C. Potential for primary prevention of Alzheimer's disease: an analysis of population-based data. Lancet Neurol 2014;13:788794.

79. Chan S, Kartha K, Yoon SS, Desmond DW, Hilal SK. Multifocal hypointense cerebral lesions on gradient-echo MR are associated with chronic hypertension. AJNR Am J Neuroradiol 1996;17:1821-1827.

80. Offenbacher H, Fazekas F, Schmidt R, Koch M, Fazekas G, Kapeller P. MR of cerebral abnormalities concomitant with primary intracerebral hematomas. AJNR Am J Neuroradiol 1996; 17:573-578.

81. Greenberg SM, Finklestein SP, Schaefer PW. Petechial hemorrhages accompanying lobar hemorrhage: detection by gradient-echo MRI. Neurology 1996;46:1751-1754.

82. Kim BJ, Lee SH. Cerebral microbleeds: their associated factors, radiologic findings, and clinical implications. J Stroke 2013; 15:153-163.

83. Kinoshita T, Okudera T, Tamura H, Ogawa T, Hatazawa J. Assessment of lacunar hemorrhage associated with hypertensive stroke by echo-planar gradient-echo T2*-weighted MRI. Stroke 2000;31:1646-1650.

84. Tsushima Y, Aoki J, Endo K. Brain microhemorrhages detected on T2*-weighted gradient-echo MR images. AJNR Am J Neuroradiol 2003;24:88-96.

85. Cordonnier C, Al-Shahi Salman R, Wardlaw J. Spontaneous brain microbleeds: systematic review, subgroup analyses and standards for study design and reporting. Brain 2007;130:19882003.

86. Werring DJ, Coward LJ, Losseff NA, Jager HR, Brown MM. Cerebral microbleeds are common in ischemic stroke but rare in TIA. Neurology 2005;65:1914-1918.

87. Jeon SB, Kwon SU, Cho AH, Yun SC, Kim JS, Kang DW. Rapid appearance of new cerebral microbleeds after acute ischemic stroke. Neurology 2009;73:1638-1644.

88. Lee SH, Lee ST, Kim BJ, Park HK, Kim CK, Jung KH, et al. Dynamic temporal change of cerebral microbleeds: long-term follow-up MRI study. PLoS One 2011;6:e25930.

89. Gregoire SM, Brown MM, Kallis C, Jager HR, Yousry TA,
Werring DJ. MRI detection of new microbleeds in patients with ischemic stroke: five-year cohort follow-up study. Stroke 2010;41:184-186.

90. Jeon SB, Kang DW, Cho AH, Lee EM, Choi CG, Kwon SU, et al. Initial microbleeds at MR imaging can predict recurrent intracerebral hemorrhage. J Neurol 2007;254:508-512.

91. Greenberg SM, Eng JA, Ning M, Smith EE, Rosand J. Hemorrhage burden predicts recurrent intracerebral hemorrhage after lobar hemorrhage. Stroke 2004;35:1415-1420.

92. Soo YO, Yang SR, Lam WW, Wong A, Fan YH, Leung HH, et al. Risk vs benefit of anti-thrombotic therapy in ischaemic stroke patients with cerebral microbleeds. J Neurol 2008;255: 1679-1686.

93. Tanaka A, Ueno Y, Nakayama Y, Takano K, Takebayashi S. Small chronic hemorrhages and ischemic lesions in association with spontaneous intracerebral hematomas. Stroke 1999;30: 1637-1642.

94. Lee SH, Bae HJ, Yoon BW, Kim H, Kim DE, Roh JK. Low concentration of serum total cholesterol is associated with multifocal signal loss lesions on gradient-echo magnetic resonance imaging: analysis of risk factors for multifocal signal loss lesions. Stroke 2002;33:2845-2849.

95. Vernooij MW, van der Lugt A, Ikram MA, Wielopolski PA, Niessen WJ, Hofman A, et al. Prevalence and risk factors of cerebral microbleeds: the Rotterdam Scan Study. Neurology 2008;70:1208-1214.

96. Reed DM. The paradox of high risk of stroke in populations with low risk of coronary heart disease. Am J Epidemiol 1990; 131:579-588

97. Dietrich WD, Busto R, Halley M, Valdes I. The importance of brain temperature in alterations of the blood-brain barrier following cerebral ischemia. J Neuropathol Exp Neurol 1990;49: 486-497.

98. Hjort N, Butcher K, Davis SM, Kidwell CS, Koroshetz WJ, Rother J, et al. Magnetic resonance imaging criteria for thrombolysis in acute cerebral infarct. Stroke 2005;36:388-397.

99. Lee SH, Bae HJ, Kwon SJ, Kim H, Kim YH, Yoon BW, et al. Cerebral microbleeds are regionally associated with intracerebral hemorrhage. Neurology 2004;62:72-76.

100. Jeong SW, Jung KH, Chu K, Bae HJ, Lee SH, Roh JK. Clinical and radiologic differences between primary intracerebral hemorrhage with and without microbleeds on gradient-echo magnetic resonance images. Arch Neurol 2004;61:905-909.

101. Imaizumi T, Honma T, Horita Y, Kawamura M, Kohama I, Miyata $\mathrm{K}$, et al. The number of microbleeds on gradient $\mathrm{T} 2{ }^{*}$ weighted magnetic resonance image at the onset of intracerebral hemorrhage. J Stroke Cerebrovasc Dis 2008;17:30-34.

102. Greenberg SM, O’Donnell HC, Schaefer PW, Kraft E. MRI 
detection of new hemorrhages: potential marker of progression in cerebral amyloid angiopathy. Neurology 1999;53:1135-1138.

103. Charidimou A, Kakar P, Fox Z, Werring DJ. Cerebral microbleeds and recurrent stroke risk: systematic review and metaanalysis of prospective ischemic stroke and transient ischemic attack cohorts. Stroke 2013;44:995-1001.

104. Lee SH, Heo JH, Yoon BW. Effects of microbleeds on hemorrhage development in leukoaraiosis patients. Hypertens Res 2005;28:895-899.

105. Lee SH, Kim BJ, Roh JK. Silent microbleeds are associated with volume of primary intracerebral hemorrhage. Neurology 2006;66:430-432.

106. Imaizumi T, Honma T, Horita Y, Kohama I, Miyata K, Kawamura M, et al. Hematoma size in deep intracerebral hemorrhage and its correlation with dot-like hemosiderin spots on gradient echo T2*-weighted MRI. J Neuroimaging 2006;16:236-242.

107. Kim BJ, Lee SH. Silent microbleeds and hemorrhagic conversion of an embolic infarction. J Clin Neurol 2007;3:147-149.

108. Kidwell CS, Saver JL, Villablanca JP, Duckwiler G, Fredieu A, Gough K, et al. Magnetic resonance imaging detection of microbleeds before thrombolysis: an emerging application. Stroke 2002;33:95-98.

109. Nighoghossian N, Hermier M, Adeleine P, Blanc-Lasserre K, Derex L, Honnorat J, et al. Old microbleeds are a potential risk factor for cerebral bleeding after ischemic stroke: a gradient-echo T2*-weighted brain MRI study. Stroke 2002;33:735742.

110. Kim HS, Lee DH, Ryu CW, Lee JH, Choi CG, Kim SJ, et al. Multiple cerebral microbleeds in hyperacute ischemic stroke: impact on prevalence and severity of early hemorrhagic trans- formation after thrombolytic treatment. AJR Am J Roentgenol 2006;186:1443-1449.

111. Kakuda W, Thijs VN, Lansberg MG, Bammer R, Wechsler L, Kemp S, et al. Clinical importance of microbleeds in patients receiving IV thrombolysis. Neurology 2005;65:1175-1178.

112. Lee SH, Kang BS, Kim N, Roh JK. Does microbleed predict haemorrhagic transformation after acute atherothrombotic or cardioembolic stroke? J Neurol Neurosurg Psychiatry 2008; 79:913-916.

113. Fiehler J, Albers GW, Boulanger JM, Derex L, Gass A, Hjort N, et al. Bleeding risk analysis in stroke imaging before thromboLysis (BRASIL): pooled analysis of $\mathrm{T} 2{ }^{*}$-weighted magnetic resonance imaging data from 570 patients. Stroke 2007;38:27382744.

114. Shoamanesh A, Kwok CS, Lim PA, Benavente OR. Postthrombolysis intracranial hemorrhage risk of cerebral microbleeds in acute stroke patients: a systematic review and metaanalysis. Int J Stroke 2013;8:348-356.

115. Boulanger JM, Coutts SB, Eliasziw M, Gagnon AJ, Simon JE, Subramaniam $S$, et al. Cerebral microhemorrhages predict new disabling or fatal strokes in patients with acute ischemic stroke or transient ischemic attack. Stroke 2006;37:911-914.

116. Werring DJ, Frazer DW, Coward LJ, Losseff NA, Watt H, Cipolotti L, et al. Cognitive dysfunction in patients with cerebral microbleeds on T2*-weighted gradient-echo MRI. Brain 2004;127:2265-2275.

117. Gregoire SM, Smith K, Jager HR, Benjamin M, Kallis C, Brown MM, et al. Cerebral microbleeds and long-term cognitive outcome: longitudinal cohort study of stroke clinic patients. Cerebrovasc Dis 2012;33:430-435. 